\title{
Correction to: Voltammetric detection of anti-HIV replication drug based on novel nanocomposite gold-nanoparticle- $\mathrm{CaCO}_{3}$ hybrid material
}

\author{
Jagriti Narang ${ }^{1} \cdot$ Nitesh Malhotra $^{2} \cdot$ Gajendra Singh $^{3} \cdot$ C. S. Pundir ${ }^{4}$ \\ Published online: 11 March 2019 \\ ๑) Springer-Verlag GmbH Germany, part of Springer Nature 2019
}

\section{Correction to: Bioprocess Biosyst Eng (2015) 38:815-822 https://doi.org/10.1007/s00449-014-1323-1}

The Figs. 2, 4 and 5 were published wrongly in this paper, due to inadvertent compilation of figures during uploading the paper. The correct Figs. 2, 4 and 5 are listed in the following:

Publisher's Note Springer Nature remains neutral with regard to jurisdictional claims in published maps and institutional affiliations.

The original article can be found online at https://doi.org/10.1007/ s00449-014-1323-1.

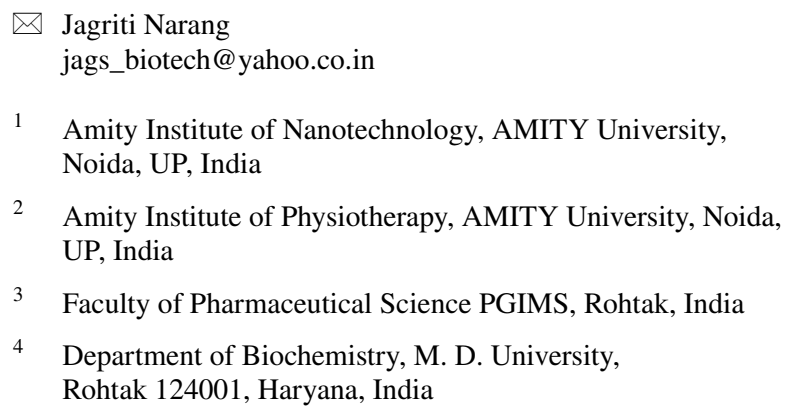

4 Department of Biochemistry, M. D. University, Rohtak 124001, Haryana, India 


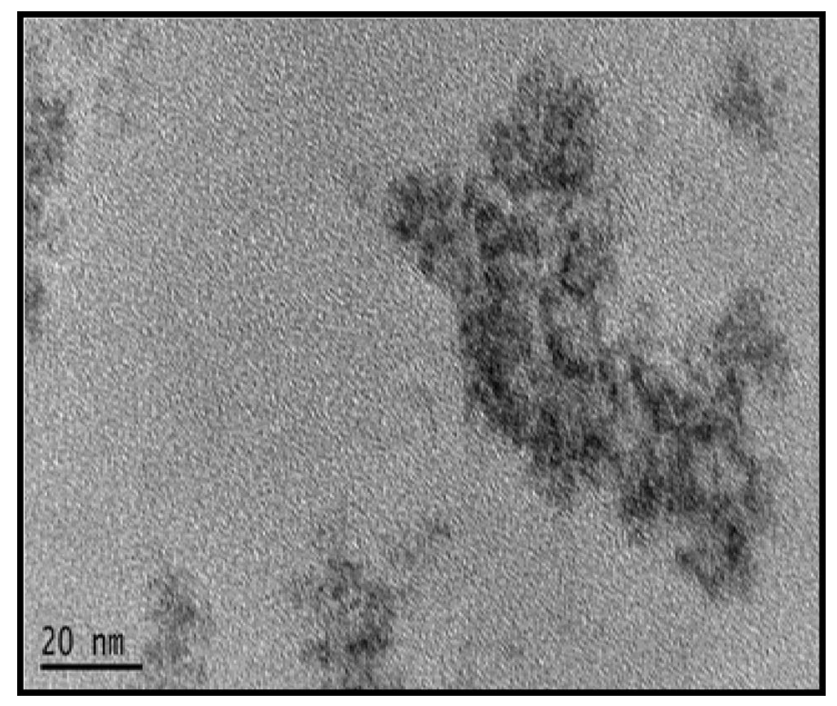

Fig. 2 Transmission electron microscope image microscope (TEM) image of AuNP-CaCO 3
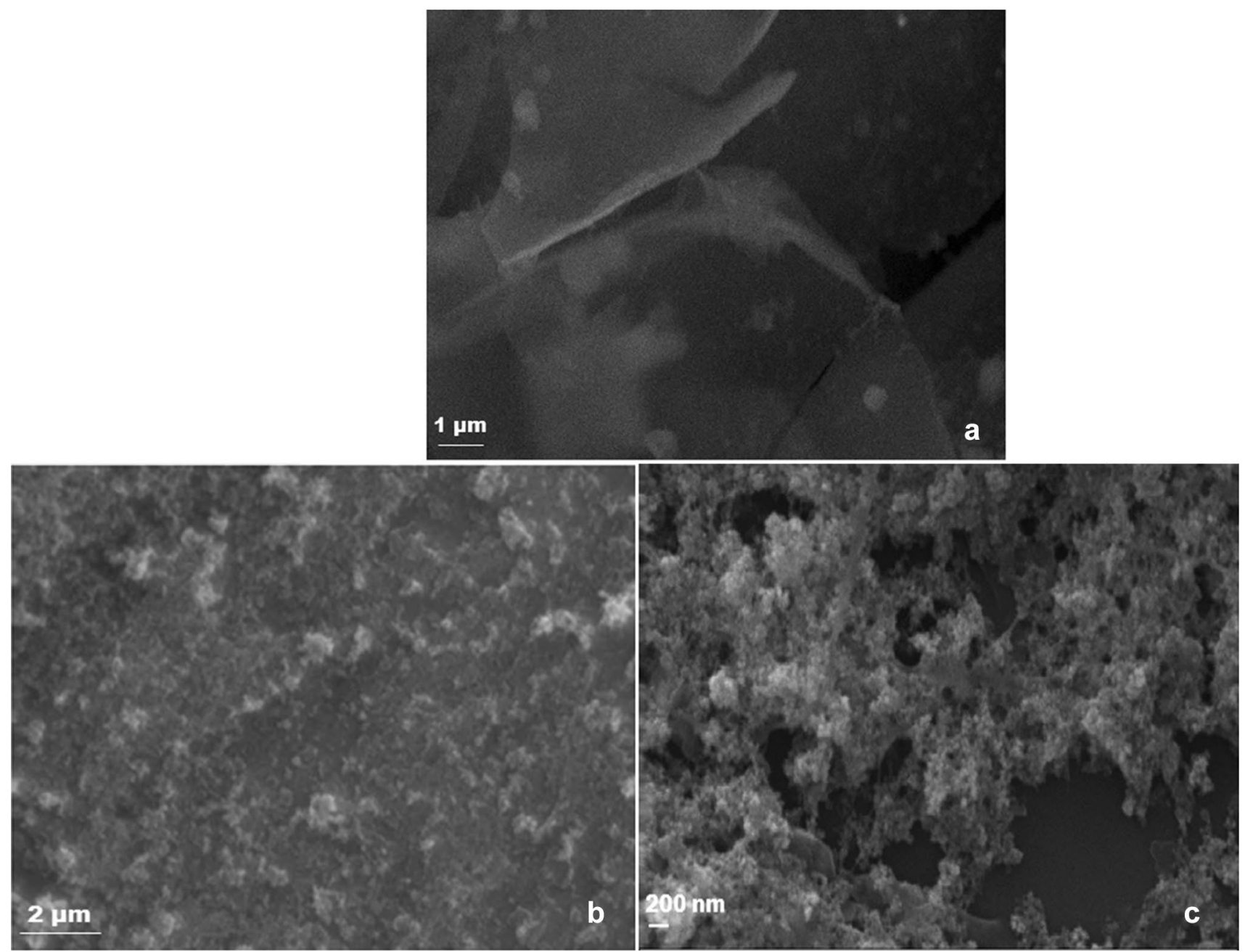

Fig. 4 SEM of a bare GCE, b AuNPs-CaCO 3 /silica sol-gel-modified GCE (c) and HRP-AuNPs-CaCO 3 /silica sol-gel-modified GCE 


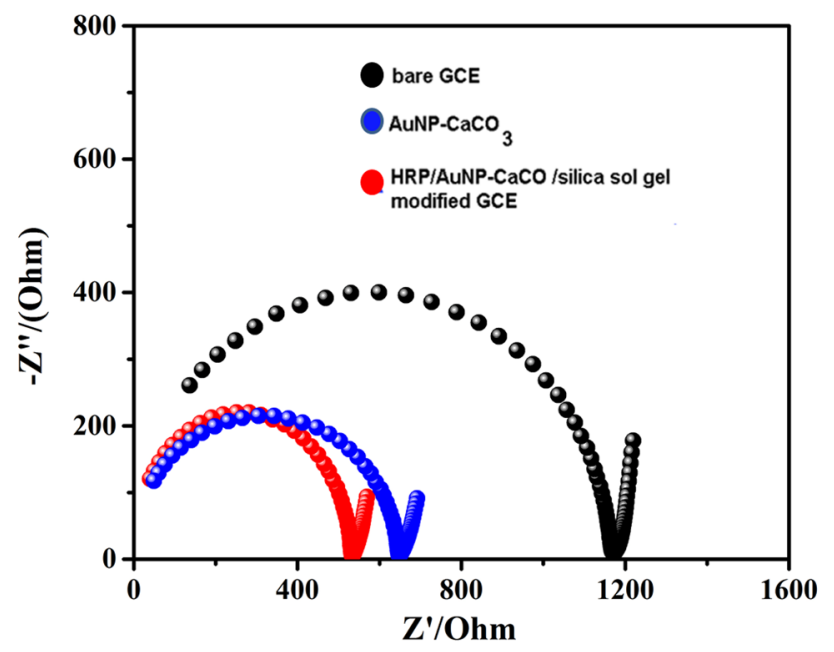

Fig. 5 EIS of (i) bare GCE (ii) AuNPs- $\mathrm{CaCO}_{3} /$ silica sol-gel-modified GCE (iii) and HRP-AuNPs- $\mathrm{CaCO}_{3} /$ silica sol-gel-modified GCE in a solution containing $1 \mathrm{mM} \mathrm{Fe}(\mathrm{CN})_{6}{ }^{3-/ 4-}$ with $0.1 \mathrm{M} \mathrm{KCl}$ at $0.20 \mathrm{mV} \mathrm{s}^{-1}$ (frequency range of $0.01 \mathrm{~Hz}-10 \mathrm{kHz}$ ) 